\title{
Clinical and pathological characteristics of 2019 novel coronavirus disease (COVID-19): a systematic reviews
}

Yaqian Mao ${ }^{[1]}$, M.D., Wei Lin ${ }^{[2]}$, M.D., Junping Wen ${ }^{[2]}$, M.D., Gang Chen ${ }^{[1][2][3]}$, M.D.

[1] Shengli Clinical Medical College of Fujian Medical University, Fuzhou, Fujian 350001, China.

[2] Department of endocrinology, Fujian Provincial Hospital, Fuzhou, Fujian 350001, China.

[3] Fujian Provincial Key Laboratory of Medical Analysis, Fujian Academy of Medical Sciences, Fuzhou Fujian, 350001, China.

Correspondence to: Gang Chen, Fujian Academy of Medical Sciences, Fuzhou 350001, China

Email: chengangfj@163.com

Tel: +86-1350933707

Date of the revision: March 6, 2020

A word count for text :2460 words 


\section{Key Points}

Question What can we learn from the clinical manifestations and pathological features of 2019 novel coronavirus disease (COVID-19)?

Findings In this review, we found COVID-19 was transmitted in a more diverse way than Severe acute respiratory syndrome (SARS). Fever, cough and Malaise/Fatigue were the most common symptoms. We also found that the SARS-CoV-2 has the same cell entry receptor ACE2 as SARS-CoV, and they have similar pathological mechanisms like Acute respiratory distress syndrome (ARDS).

Meaning This review aims to give people a more comprehensive understanding of COVID-19 and to continuously improve the level of prevention, control, diagnosis and treatment.

\section{Abstracts}

Importance In 2002-2003, a severe pulmonary infectious disease occurred in guangdong, China. The disease was caused by severe acute respiratory syndrome coronavirus (SARS-CoV), 17 years apart, also happen in China, and also a novel coronavirus (SARS-CoV-2), this epidemic has posed a significant hazard to people's health both China and the whole world.

Objective Summarized the latest epidemiological changes, clinical manifestations, auxiliary examination and pathological characteristics of COVID-19.

Evidence Review PubMed database were searched from 2019 to 2020 using the index terms "novel coronavirus" or "COVID-19" or "2019-nCoV" or "SARS-CoV-2" 
and synonyms. Articles that reported clinical characteristics, laboratory results, imageological diagnosis and pathologic condition were included and were retrospectively reviewed for these cases. This paper adopts the method of descriptive statistics.

Results 34 COVID-19-related articles were eligible for this systematic review , Four of the articles were related to pathology. We found that Fever (86.0\%), cough (63.9\%) and Malaise/Fatigue (34.7\%) were the most common symptoms in COVID-19. But in general, the clinical symptoms and signs of COVID-19 were not obvious. Compared with SARS, COVID-19 was transmitted in a more diverse way. The mortality rates of COVID-19 were $2.5 \%$, and the overall infection rate of healthcare worker of COVID-19 was 3.9\%. We also found that the pathological features of COVID-19 have greatly similar with SARS, which manifested as ARDS. But the latest pathological examination of COVID-19 revealed the obvious mucinous secretions in the lungs.

Interpretation The clinical and pathological characteristics of SARS and COVID-19 in China are very similar, but also difference. The latest finds of pathological examination on COVID-19 may upend existing treatment schemes, so the early recognition of disease by healthcare worker is very important.

\section{Introduction}

In December 2019, a group of unidentified pneumonia patients was found to be linked to a seafood wholesale market in wuhan, China ${ }^{[1]}$. By analyzing samples from 
pneumonia patients, we identified a previously unknown subcoronavirus, which we named 2019-novel coronavirus (2019-nCoV). WHO has officially named the virus severe acute respiratory syndrome coronavirus 2 (SARS-CoV-2) and the disease corona virus disease 2019 (COVID-19) ${ }^{[2]}$. By Mar 8, 2020, more than 105586 cases of COVID-19 pneumonia had been reported in countries and regions around the world , the cumulative death toll stands at $3584^{[3]}$. The United States, Australia, Germany, Vietnam, South Korea, Canada, Brazil, Nepal and Japan over 102 countries are also seeing increasing Numbers of travel-related cases and human-to-human transmission $^{[3-11]}$. COVID-19 is transmitted primarily through droplets and contact, recent studies ${ }^{[4,12]}$ showed that SARS-CoV-2 was detected in stool samples of patients, which makes it possible for gastrointestinal transmission.

Seventeen years ago, a severe acute respiratory syndrome (SARS) happened in Guangdong Province, China, and soon spread to other countries and regions ${ }^{[13-16]}$. By the end of the outbreak, 26 countries had reported 8,098 possible SARS cases and 774 deaths $^{[14]}$. SARS-CoV and SARS-CoV-2 are both enveloped RNA viruses and widely distributed in humans, other mammals and birds. Recent studies analysis showed that the novel coronavirus had $78 \%$ nucleotide homology with human SARS-CoV ${ }^{[17,18]}$. As. more and more COVID-19 cases are diagnosed, we find that SARS and COVID-19 share many similarities in clinical manifestations, epidemiology, and mode of transmission. At present, while the epidemic in China is gradually under control, Europe and the Middle East have shown a rapid spread of the epidemic. For example, the number of infections in South Korea, Italy, Iran and other 
countries has soared recently ${ }^{[3]}$. So far, our understanding of COVID-19 remained to be limited, Especially in pathology. This report summarizes the initial clinical description and Pathological discovery of SARS and COVID-19 in different countries. We also compared the pathological features of SARS-CoV and SARS-CoV-2 to provide a reference for the diagnosis and treatment of COVID-19 by describing and emphasizing the characteristic changes of SARS-CoV.

\section{Methods}

This study aimed to summary the case of COVID-19 on clinical features, epidemiological findings, laboratory and imageological examination, pathological studies and treatment options in different countries.

\section{Search strategy}

This study was a review that was conducted in 2020. Searches were done in scientific databases of PubMed, based on the combination of related keywords based of Mesh terms (Table 1). One researcher (Y.Q.M), a professional clinician searched PubMed for all published articles regarding COVID-19 up to March 9, 2020. A second researcher (W. L), a professional clinician with expertise in systematic reviews, repeated the first reviewer's search independently. Both searches agreed completely. All steps of searches were done based on the Preferred Reporting Items for Systematic Reviews and Meta-Analyses (PRISMA) checklist. The searches were limited to papers published in the English and Chinese language. Institutional review board approval and informed consent were not obtained given that the study was a 
systematic review of the literature, we limited our study to published information and did not engage with any human subjects.

\section{Inclusion and exclusion criteria}

The inclusion criteria were original articles, retrospective case series and case report of COVID-19 infection, including clinical features, epidemiological findings, laboratory and imageological examination, treatment options or pathological studies. Exclusion criteria were unavailable full text, no target observations and other article types, Other article types included review articles, comment, news, etc. Also conference articles were excluded. The data extraction of categories, including the author's name, publication year, countries, age, sex, clinical features, epidemiological findings, laboratory and imageological examination, treatment options, pathological studies, etc. After data extraction, we summarized and reported the findings in tables and figures according to the objectives of the study. Two researchers (Y.Q.M and W.L who were specialist physicians) reviewed each of these articles in detail. Each researcher identified every article that concerned clinical characteristics or pathologic studies of COVID-19 infection. These search results are submitted to third parties (J.W.P who was a professionally trained physician), who review discrepancies and make decisions in the event of disagreement.

\section{Statistical analysis}

Categorical variables were summarized as frequencies and percentages, and continuous variables were described using a range, median and interquartile ranges (IQR) values, Mean and standard deviation (SD). 


\section{Results}

As of March 9, 2020, we identified 34 studies, Among them, $33 \operatorname{articles}^{[2,4-11,19-42]}$ come from the PubMed database, and one article ${ }^{[43]}$ about pathology comes from a Chinese journal (Figure 1). Three of the articles were related to pathology ${ }^{[41-43]}$. The characteristics of 34 studies are shown in Table 2. Articles on the characteristics of COVID-19 mainly came from China, as well as from countries with a small number of current case reports, such as the United States, Germany, Australia, Vietnam, Thailand, Japan, Canada, Brazil, Nepal and South Korea.

\section{Demographic and clinical characteristics}

Demographic and clinical characteristics are shown in Table 3. In COVID-19, we found $3.9 \%$ were health workers, and $51.7 \%$ were male (male: female=1.07:1). The most common clinical manifestation of COVID-19 were Fever (86.0\%), Cough (63.9\%), Malaise/Fatigue/Confusion (34.7\%), Sputum production (28.9\%), Shortness of breath (19.7\%) and Myalgia (18.8\%), whereas diarrhea (5.7\%) and Nausea/vomiting (6.1\%) were rare. $26.7 \%$ of patients in COVID-19 had at least one underlying disorder (i.e., hypertension, diabetes, Cardiovascular disease, etc).

\section{Imaging and laboratory findings at presentation}

Table 3 shows the laboratory and Imaging findings In COVID-19. In these review we found the most common, patterns on chest imaging findings were ground-glass opacity $(60.9 \%)$ and pulmonary consolidation or exudation $(37.0 \%), 19.5 \%$ were unilateral pneumonia and $68.8 \%$ were bilateral pneumonia. $64.2 \%, 29.1 \%$ and $24.3 \%$ 
of patients had lymphopenia, leucopenia and thrombocytopenia, respectively.

\section{Treatment and outcomes}

Table 3 shows the treatment and outcomes. In this review we found that in COVID-19, oxygen therapy, antiviral therapy, antibiotic therapy, the use of corticosteroids or immunoglobulin were in $56.1 \%, 51.2 \%, 62.9 \%, 22.0 \%$ and $16.8 \%$ of patients, respectively. Another $1.4 \%$ and $2.5 \%$ of people use of extracorporeal membrane oxygenation and continuous renal-replacement therapy. The death toll and severe patients of COVID-19 were $18.4 \%$ and $2.5 \%$.

\section{Mode of transmission}

Before the closes of Huanan seafood market on January 1, 2020. people contracted the disease mainly through contact with host animals carrying the virus ${ }^{[24]}$, Subsequently, infected people spread the virus to their families, communities through human-to-human transmission and contact transmission. Other countries are also seeing increasing numbers of travel-related imported cases and human-to-human transmission.

\section{Pulmonary pathology}

Table 4 summarizes the pulmonary pathological features of COVID-19. The pathology showed that the manifestations of COVID-19 were similar to SARS. But the latest pathological examination of COVID-19 revealed the obvious mucinous secretions in the lungs.

\section{Discussion}


SARS-CoV and SARS-CoV-2 are both belong to the $\beta$ coronavirus family, which share $78 \%$ of their nucleotide homology ${ }^{[18]}$. As more and more confirmed cases of COVID-19 have been reported, we found that SARS and COVID-19 have great similarities in clinical manifestations, laboratory examinations and chest imaging.

\section{Infectious source}

Current studies have shown that SARS-CoV-2 is mainly related to wildlife trafficking in Huanan seafood market in China. A study by Chan et al found that SARS-CoV-2 is most closely related to coronaviruses found in horseshoe bats in China ${ }^{[44]}$.The SARS outbreak in 2002 and the Middle East respiratory syndrome (MERS) outbreak in 2012 have demonstrated the possibility of coronavirus transmission from animals to humans ${ }^{[45,46]}$.

It is currently believed that whether SARS or COVID-19, the main source of infection is people infected with coronavirus. in the early report of 41 confirmed cases of COVID-19, 27 reported exposure to the Huanan seafood market ${ }^{[24]}$. But since the closure of the seafood market on Jan 1, 2020, more and more new cases have been reported to be associated with contact with confirmed patients which stress the importance of human-to-human transmission. However, it's worth noting that there were some people uninfected in close contacts with SARS or COVID-19 ${ }^{[12,13,16]}$. Therefore, whether genetic susceptibility exists or not needs further study.

\section{Route of transmission}

In this study, we found COVID-19 were mainly transmitted by droplets and contact, showing human-to-human transmission, family aggregation spread and 
nosocomial infection. It is worth noting that COVID-19 has a more diverse mode of transmission that can manifest itself as asymptomatic infection ${ }^{[7]}$, something that has not previously been seen in $\mathrm{SARS}^{[47]}$. Because of the absence of symptoms, it is difficult to detect and isolate carriers in time, which makes it more difficult to control the spread of the disease ${ }^{[47,48]}$. Recent studies have found that SARS-CoV-2 can be detected in the feces of patients, indicating that the possibility of fecal-oral transmission $^{[4,12]}$. There have been reports of infections in newborns ${ }^{[2]}$, but more studies are needed to confirm the presence of vertical transmission. A study of nine pregnant women ${ }^{[2]}$ which tested the amniotic fluid, cord blood, neonatal throat swabs and breast milk of six patients for SARS-CoV, all of which were negative and did not support mother-to-child transmission. Human-to-human, asymptomatic infection and possible mother-to-child transmission and fecal-oral transmission are the causes of the widespread spread of the disease. So, the early recognition of COVID-19 in different countries can reduces transmission risk and increases understanding of SARS-CoV-2, to inform national and global response actions.

\section{Susceptible population}

Through the summary analysis of the pneumonia, we found that COVID-19 had a general susceptibility, However, it should be noted that cases ${ }^{[2]}$ of infection in pregnant women, newborns, infants and children have been reported successively. The reason was considered to be related to the special immune tolerance state of pregnant women during pregnancy ${ }^{[2]}$ and the low immune function of children and infants ${ }^{[48]}$. Elderly people with basic diseases are at high risk of infection with COVID-19 ,due to 
the low body defense against infection, it is easy to develop severe pneumonia once infected with COVID-19 ${ }^{[12,21]}$.

\section{Clinical manifestations, auxiliary examination and treatment}

Through the study of COVID-19 in different countries, we found that pneumonia were mainly characterized by fever, accompanied by different degrees of cough, dyspnea, fatigue and discomfort. However, the clinical symptoms of COVID-19 were not obvious. COVID-19 patients with mild symptoms are easy to be overlooked, so it is necessary to take active and effective isolation measures for suspected patients or close contacts as early as possible. Furthermore, laboratory tests showed that patients with COVID-19 may had lymphopenia, leukopenia, and thrombocytopenia, along with elevated levels of liver enzymes and lactate dehydrogenase.

On imaging, COVID-19 was mainly manifested as multiple ground-glass shadows. A CT scan of 29 patients with COVID-19 revealed a single or multiple patchy frosted glass shadow with septum thickening in typical case of COVID-19.As the disease progresses, the lesion increases and the scope expands, and frosted glass shadows coexist with solid or striated shadows ${ }^{[29]}$. An imaging study of 81 people found that abnormal chest imaging could occur even in asymptomatic patients and progressed rapidly from focal unilateral to diffuse bilateral within $1-3$ weeks ${ }^{[26]}$. Since the early imaging changes of COVID-19 were not obvious, high resolution chest CT examination should be performed as soon as possible for suspected patients to clarify. At present, the treatment of COVID-19 is lack of specific drugs and mainly focuses on support treatment. Therefore, early detection, early isolation, early diagnosis and 
early treatment are the key measures to control infectious diseases. Our clinical and pathological review of COVID-19 can help healthcare worker to formulate a timely therapeutic strategy for similar patients and reduce mortality

\section{Pathological characteristics}

SARS-CoV-2 has been identified as a sister virus to SARS-CoV, a SARS-related coronavirus (SARSr-CoV). SARS-CoV and SARS-CoV-2 have been shown to infect human respiratory epithelial cells through the interaction of viral $\mathrm{S}$ proteins and angiotensin-converting enzyme 2 receptors on human cells ${ }^{[26,49]}$. Therefore, it is speculated that they may have the same pathological changes. The early pathology of SARS found ${ }^{[50,51]}$ that SARS-CoV widespreadly existed in the epithelium of the digestive tract, the epithelium of the distal convoluted tubules of the kidney, and the sweat glands of the skin, suggesting that in addition to respiratory transmission, SARS might also be transmitted through contact between the patient's feces, urine and skin. which also provided a new way to prevent the transmission of COVID-19. In addition, Ding et al ${ }^{[50,51]}$ also found SARS-CoV in systemic endocrine gland, Because SARS-CoV and SARS-CoV-2 have the same mechanism of action, they can cause rapid production of multiple cytokines in body fluids after infection with microorganisms, leading to acute respiratory distress and multiple organ failure. This also explains why most covid-19 patients have mild symptoms at the onset of the disease, while some are suddenly worse after being diagnosed in hospital, which may be related to the body producing too many cytokines after the disease, leading to "cytokine storm" in the body. 
$\mathrm{Xu}$ et $\mathrm{al}^{[42]}$ and Tian et $\mathrm{al}^{[41]}$ found diffuse alveolar injury, transparent membrane formation and pulmonary edema in the early pulmonary puncture pathology of COVID-19 patients, which was similar to the pathological manifestations of SARS. However, it is worth noting that the pathology of COVID-19 also shows fibromyxoid exudation and the formation of thick "mucus plugs". The first autopsy, performed by liu's team ${ }^{[43]}$, found a large amount of sticky secretions spilling out of the alveoli, with fibrous cords visible. As of February 25, Liu's team completed a preliminary anatomical diagnosis of three of the 11 cases, all of which found mucinous secretions in the lungs of the deceased. This finding is a warning for clinical treatment. If the mucus components are not dissolved, oxygen alone may not achieve the goal, and sometimes may be counterproductive to increase the hypoxia of patients.

\section{Limitations}

This study has several limitations, first, among those cases, most patients are still hospitalized at the time of paper published. Therefore, it is difficult to accurate assess number of deaths and severe cases, and risk factors for poor outcome. so continued observations of the process and prognosis of the disease are needed. second,So far, many foreign reports on COVID-19 have been individual cases, making comparisons difficult. This paper mainly uses descriptive analysis to review and summarize the case.

\section{Conclusion}


The source, intermediate host, transmission route and incubation period of SARS-CoV-2 are not fully understood. Knowledge of the virus remains elusive and unpredictable. Therefore, early pathological examination is the most direct means to uncover the true face of SARS-CoV-2. Now the outbreak of COVID-19 constitutes an epidemic threat in China and Worldwide. It is important for public medical institutions, health care workers, and the public to have an early recognition of COVID-19 so that coordinated and effective actions can help prevent additional cases or poor health outcomes.

\section{Acknowledgements}

We greatly appreciate the efforts of all the hospital employees and their families at the Fujian Provincial Hospital and affiliated Hospital of Fujian Medical University, who are working tirelessly during this outbreak.

\section{Article Information}

Author Contributions: Gang Chen had full access to all of the data in the study and takes responsibility for the integrity of the data and the accuracy of the data analysis.

Concept and design: Yaqian Mao, Wei Lin, , Gang Chen.

Acquisition, analysis, or interpretation of data: Yaqian Mao, Wei Lin, Junping Wen

Drafting of the manuscript: Yaqian Mao, Gang Chen

Critical revision of the manuscript for important intellectual content: Yaqian

Mao, Gang Chen 
Statistical analysis: Yaqian Mao

Administrative, technical, or material support: None

Supervision: Gang Chen

Conflict of Interest Disclosures: The authors declare that they have no conflicts of interest for this work.

Funding/Support: None

\section{Reference}

1. Chen N, Zhou M, Dong X, et al. Epidemiological and clinical characteristics of 99 cases of 2019 novel coronavirus pneumonia in Wuhan, China: a descriptive study.

Lancet. 2020. 202002 15;395(10223). DOI : 10.1016/S0140-6736(20)30211-7.

2. Chen H, Guo J, Wang C, et al. Clinical characteristics and intrauterine vertical transmission potential of COVID-19 infection in nine pregnant women: a retrospective review of medical records. Lancet. 2020 Mar 07;395(10226). DOI : 10.1016/S0140-6736(20)30360-3.

3. World Health Organization. Coronavirus disease (COVID-2019) situation reports. https://www.who.int/emergencies/diseases/novel-coronavirus-2019/situation-repor ts. 08 March 2020.

4. Holshue M L, Debolt C, Lindquist S, et al. First Case of 2019 Novel Coronavirus in the United States. N Engl J Med. 2020. 202003 05;382(10). DOI : 10.1056/NEJMoa2001191. 
5. Nco V N I R S T. 2019-nCoV acute respiratory disease, Australia: Epidemiology Report 1 (Reporting week 26 January - 1 February 2020). Commun Dis Intell (2018). 2020 Feb 06;44. DOI : 10.33321/cdi.2020.44.13.

6. Phan L T, Nguyen T V, Luong Q C, et al. Importation and Human-to-Human Transmission of a Novel Coronavirus in Vietnam. N Engl J Med. 202002 27;382(9). DOI : 10.1056/NEJMc2001272.

7. Rothe C, Schunk M, Sothmann P, et al. Transmission of 2019-nCoV Infection from an Asymptomatic Contact in Germany. N Engl J Med. 2020.2020 03 05;382(10). DOI : 10.1056/NEJMc2001468.

8. Kim J Y, Choe P G, Oh Y, et al. The First Case of 2019 Novel Coronavirus Pneumonia Imported into Korea from Wuhan, China: Implication for Infection Prevention and Control Measures. J Korean Med Sci. 2020, 35(5). DOI : 10.3346/jkms.2020.35.e61.

9. Aj R-M, V G, Jp E-A, et al. COVID-19 in Latin America: The implications of the first confirmed case in Brazil [Published online February 29, 2020]. Travel Med Infect Dis. DOI : 10.1016/j.tmaid.2020.101613.

10. R S, S S, P K, et al. Nepal's First Case of COVID-19 and public health response [Published online March 03, 2020]. Tree Physiol. DOI :10.1093/treephys/tpaa024.

11. Wk S, L S, Ge C, et al. First imported case of 2019 novel coronavirus in Canada, presenting as mild pneumonia. Lancet. 395(10225), 734. DOI : 10.1016/S0140-6736(20)30370-6.

12. Kim JY, Ko JH, Kim Y, et al. Viral Load Kinetics of SARS-CoV-2 Infection in 
medRxiv preprint doi: https://doi.org/10.1101/2020.02.20.20025601; this version posted March 19, 2020. The copyright holder for this preprint (which was not certified by peer review) is the author/funder, who has granted medRxiv a license to display the preprint in perpetuity.

All rights reserved. No reuse allowed without permission.

First Two Patients in Korea. J Korean Med Sci. 2020;35(7):e86. DOI:10.3346/jkms.2020.35.e86.

13. Tsang K W, Ho P L, Ooi G C, et al. A cluster of cases of severe acute respiratory syndrome in Hong Kong. N Engl J Med. 2003, 348(20): 1977-1985. DOI : 10.1056/NEJMoa030666.

14. Vu H T, Leitmeyer K C, Le D H, et al. Clinical description of a completed outbreak of SARS in Vietnam, February-May 2003. Emerg Infect Dis. 2004, 10(2): 334-338. DOI : 10.3201/eid1002.030761

15. Hsu L Y, Lee C C, Green J A, et al. Severe acute respiratory syndrome (SARS) in Singapore: clinical features of index patient and initial contacts. Emerg Infect Dis. 2003, 9(6): 713-717. DOI: 10.3201/eid0906.030264

16. Poutanen S M, Low D E, Henry B, et al. Identification of severe acute respiratory syndrome in Canada. N Engl J Med. 2003, 348(20): 1995-2005. DOI: 10.1056/NEJMoa030634

17. Lu R, Zhao X, Li J, et al. Genomic characterisation and epidemiology of 2019 novel coronavirus: implications for virus origins and receptor binding. Lancet. 202002 22;395(10224). DOI: 10.1016/S0140-6736(20)30251-8

18. Special Expert Group for Control of the Epidemic of Novel Coronavirus Pneumonia of the Chinese Preventive Medicine Association.(2020). [An update on the epidemiological characteristics of novel coronavirus pneumonia ( COVID-19 ) ]. Zhonghua Liu Xing Bing Xue Za Zhi, 41(2), 139-144. DOI: 10.3760/cma.j.issn.0254-6450.2020.02.002. 
19. Pongpirul W A, Pongpirul K, Ratnarathon A C, et al. Journey of a Thai Taxi Driver and Novel Coronavirus [Published online February 12, 2020]. N Engl J Med. DOI:10.1056/NEJMc2001621.

20. Arashiro T, Furukawa K, Nakamura A. COVID-19 in 2 Persons with Mild Upper Respiratory Symptoms on a Cruise Ship, Japan [Published online February 26, 2020]. Emerging Infect. Dis. DOI:10.3201/eid2606.200452.

21. Wang D, Hu B, Hu C, et al. Clinical Characteristics of 138 Hospitalized Patients With 2019 Novel Coronavirus-Infected Pneumonia in Wuhan, China [Published online February7,2020]. JAMA. DOI: 10.1001/jama.2020.1585.

22. Chen N, Zhou M, Dong X, et al. Epidemiological and clinical characteristics of 99 cases of 2019 novel coronavirus pneumonia in Wuhan, China: a descriptive study. Lancet. 2020, 395(10223): 507-513. DOI: 10.1016/S0140-6736(20)30211-7

23. Guan W J, Ni Z Y, Hu Y, et al. Clinical Characteristics of Coronavirus Disease 2019 in China [Published Online February 28, 2020]. N Engl J Med. DOI: 10.1056/NEJMoa2002032.

24. Huang C, Wang Y, Li X, et al. Clinical features of patients infected with 2019 novel coronavirus in Wuhan, China [ Published Online January 24, 2020 ]. Lancet. DOI: 10.1016/S0140-6736(20)30183-5.

25. Novel Coronavirus Pneumonia Emergency Response Epidemiology Team.(2020). [The epidemiological characteristics of an outbreak of 2019 novel coronavirus diseases (COVID-19) in China]. Zhonghua Liu Xing Bing Xue Za Zhi, 2020, 41(2), 145-151. DOI:10.3760/cma.j.issn.0254-6450.2020.02.003 
26. H S, X H, N J, et al. Radiological findings from 81 patients with COVID-19 pneumonia in Wuhan, China: a descriptive study [Published Online February 24, 2020]. Lancet Infect Dis. DOI:10.1016/S1473-3099(20)30086-4.

27. Q L, X G, P W, et al. Early Transmission Dynamics in Wuhan, China, of Novel Coronavirus-Infected Pneumonia [Published Online January 29, 2020]. N Engl J Med. DOI:10.1056/NEJMoa2001316.

28. Song F, Shi N, Shan F, et al. Emerging Coronavirus 2019-nCoV Pneumonia [Published Online February 06, 2020]. Radiology. DOI: 10.1148/radiol.2020200274.

29. Chen L, Liu H G, Liu W, et al. [Analysis of clinical features of 29 patients with 2019 novel coronavirus pneumonia]. Zhonghua Jie He He Hu Xi Za Zhi. 2020, 43(0): E005. DOI:10.3760/cma.j.issn.1001-0939.2020.0005.

30. Zhou F, Yu T, Du R, et al. Clinical course and risk factors for mortality of adult inpatients with COVID-19 in Wuhan, China: a retrospective cohort study [Published Online March 9, 2020]. Lancet. DOI:10.1016/s0140-6736(20)30566-3.

31. Xw X, Xx W, Xg J, et al. Clinical findings in a group of patients infected with the 2019 novel coronavirus (SARS-Cov-2) outside of Wuhan, China: retrospective case series. BMJ. 2020;368:m606. DOI:10.1136/bmj.m606.

32. Yang W, Cao Q, Qin L, et al. Clinical characteristics and imaging manifestations of the 2019 novel coronavirus disease (COVID-19):A multi-center study in Wenzhou city, Zhejiang, China [Published Online February 26, 2020]. J Infect. DOI: 10.1016/j.jinf.2020.02.016. 
33. Yh X, Jh D, Wm A, et al. Clinical and computed tomographic imaging features of novel coronavirus pneumonia caused by SARS-CoV-2 [Published Online February 25, 2020]. J Infect. DOI:10.1016/j.jinf.2020.02.017.

34. Wang D, Ju X L, Xie F, et al. Clinical analysis of 31 cases of 2019 novel coronavirus infection in children from six provinces (autonomous region) of northern China. Zhonghua er ke za zhi. 2020, 58(4): E011-E011. DOI:10.3760/cma.j.cn112140-20200225-00138.

35. K L, Yy F, Y D, et al. Clinical characteristics of novel coronavirus cases in tertiary hospitals in Hubei Province [Published Online February 07, 2020]. Chin. Med. DOI: $10.1097 / C M 9.0000000000000744$.

36. Jj Z, X D, Yy C, et al. Clinical characteristics of 140 patients infected with SARS-CoV-2 in Wuhan, China[Published Online February 19, 2020]. Allergy.DOI:10.1111/all.14238.

37. W Z, Z Z, X X, et al. Relation Between Chest CT Findings and Clinical Conditions of Coronavirus Disease (COVID-19) Pneumonia: A Multicenter Study [Published Online March 03, 2020]. AJR Am J Roentgenol. DOI:10.2214/AJR.20.22976.

38. Yang X, Yu Y, Xu J, et al. Clinical course and outcomes of critically ill patients with SARS-CoV-2 pneumonia in Wuhan, China: a single-centered, retrospective, observational study. Lancet Respir Med. 2020: S2213-2600(2220)30079-30075. DOI: $10.1016 / \mathrm{S} 2213-2600(20) 30079-5$.

39. Tian S, Hu N, Lou J, et al. Characteristics of COVID-19 infection in Beijing. J. 
Infect. 2020: S0163-4453(0120)30101-30108. DOI: 10.1016/j.jinf.2020.02.018.

40. Xu X, Yu C, Qu J, et al. Imaging and clinical features of patients with 2019 novel coronavirus SARS-CoV-2 [Published Online February 28, 2020]. Eur. J. Nucl. Med. Mol. Imaging. DOI:10.1007/s00259-00020-04735-00259.

41. Tian S, Hu W, Niu L, et al. Pulmonary pathology of early phase 2019 novel coronavirus (COVID-19) pneumonia in two patients with lung cancer [Published Online February 27, 2020]. J Thorac Oncol. DOI:10.1016/j.jtho.2020.02.010.

42. Xu Z, Shi L, Wang Y, et al. Pathological findings of COVID-19 associated with acute respiratory distress syndrome [Published Online February 18, 2020]. Lancet Respir Med. DOI:10.1016/S2213-2600(20)30076-X.

43. Liu Qian W R, Qu Guoqiang, Wang Yunyun, et al. A report on the general observation of the necropsy of a newly developed coronavirus pneumonia. Fa Yi Xue Za Zhi. 2020. 1004-5619 ( 2020 ) 01-0. DOI : 10.12116/j.issn.1004-5619.2020.01.00.

44. Chan J F, Yuan S, Kok K H, et al. A familial cluster of pneumonia associated with the 2019 novel coronavirus indicating person-to-person transmission: a study of a family cluster. Lancet. 2020, 395(10223): 514-523. DOI:10.1016/S0140-6736(20)30154-9.

45. Cui J, Li F, Shi Z L. Origin and evolution of pathogenic coronaviruses. Nat Rev Microbiol, 2019, 17(3): 181-192. DOI: 10.1038/s41579-018-0118-9.

46. S C, Md V K, S R, et al. Transmission scenarios for Middle East Respiratory Syndrome Coronavirus (MERS-CoV) and how to tell them apart. Euro 
medRxiv preprint doi: https://doi.org/10.1101/2020.02.20.20025601; this version posted March 19, 2020. The copyright holder for this preprint (which was not certified by peer review) is the author/funder, who has granted medRxiv a license to display the preprint in perpetuity.

All rights reserved. No reuse allowed without permission.

Surveill .2013 Jun 13;18(24).

47. Mahase E. China coronavirus: mild but infectious cases may make it hard to control outbreak, report warns. BMJ. 2020, 368: m325.DOI: 10.1136/bmj.m325

48. Wang F-S, Zhang C. What to do next to control the 2019-nCoV epidemic?. The Lancet. 2020, 395(10222): 391-393. DOI:10.1016/S0140-6736(20)30300-7.

49. Oudit G Y, Kassiri Z, Jiang C, et al. SARS-coronavirus modulation of myocardial ACE2 expression and inflammation in patients with SARS. Eur J Clin Invest, 2009, 39(7): 618-625. DOI: 10.1111/j.1365-2362.2009.02153.x.

50. Ding Y-Q, Wang H-J, Shen H, et al. Study on etiology and pathology of severe acute respiratory syndrome. Zhonghua bing li xue za zhi. 2003, 32(3): 195-200.

51. He L, Ding Y-Q, Che X-Y, et al. Expression of the monoclonal antibody against nucleocapsid antigen of SARS-associated coronavirus in autopsy tissues from SARS patients. Di 1 jun yi da xue xue bao.2003, 23(11): 1128-1130.

\section{Pictures and tables}


medRxiv preprint doi: https://doi.org/10.1101/2020.02.20.20025601; this version posted March 19, 2020. The copyright holder for this preprint (which was not certified by peer review) is the author/funder, who has granted medRxiv a license to display the preprint in perpetuity.

All rights reserved. No reuse allowed without permission.

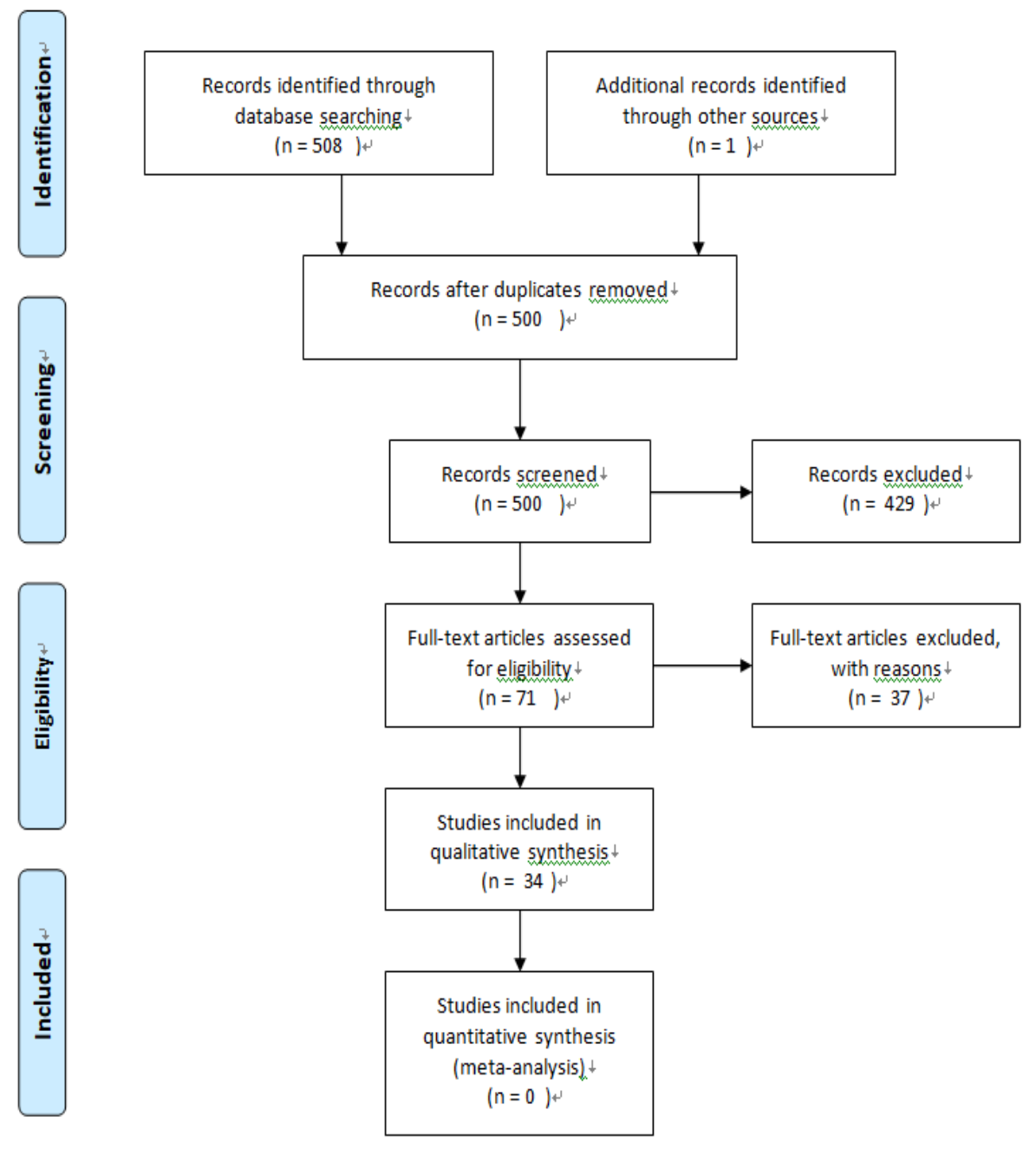

Figure 1 Flow Diagram for Selection of Studies 
medRxiv preprint doi: https://doi.org/10.1101/2020.02.20.20025601; this version posted March 19, 2020. The copyright holder for this preprint (which was not certified by peer review) is the author/funder, who has granted medRxiv a license to display the preprint in perpetuity.

All rights reserved. No reuse allowed without permission.

Table 1 Search strategy of the research

\section{Search strategy}

\begin{tabular}{|c|c|}
\hline Database & PubMed \\
\hline Limits & Language (in English or Chinese), Species (studies on humans) \\
\hline Data & 2019 to March 9, 2020 \\
\hline \#1 (MeSH) & severe acute respiratory syndrome coronavirus 2 \\
\hline \#2 (Entry Terms) & $\begin{array}{l}\text { "Wuhan coronavirus" or "Wuhan seafood market pneumonia virus" } \\
\text { or "COVID } 19 \text { virus" or "COVID-19 virus" or "coronavirus disease } \\
2019 \text { virus" or "SARS-CoV-2" or "SARS 2" or "2019-nCoV" or } \\
\text { "2019 novel coronavirus" }\end{array}$ \\
\hline Search & $\# 1$ or \#2 \\
\hline
\end{tabular}


Table2:Summary the characteristics of 34 studies that analysed the clinical or pathological characteristics of COVID-19 in different countries.

\begin{tabular}{|c|c|c|c|c|c|c|c|c|c|c|}
\hline $\mathrm{ID}^{1}$ & Study & Year & Country & $\begin{array}{l}\mathrm{SS}^{2} \\
\text { (n) }\end{array}$ & $\begin{array}{c}\text { Age (days, } \\
\text { months and years) }\end{array}$ & $\begin{array}{c}\text { Sex/Male } \\
(\mathrm{n}, \%)\end{array}$ & $\begin{array}{c}\text { Healthcare } \\
\text { worker (n, \%) }\end{array}$ & $\begin{array}{c}\text { Severe } \\
\text { patients }(\mathrm{n}, \%)\end{array}$ & $\begin{array}{l}\text { Death } \\
\text { toll(n, \%) }\end{array}$ & Mode of Transmission \\
\hline 1 & Kim, Jin Yong. & 2020 & Korea $^{[8]}$ & 1 & 35 & 0 & 0 & 0 & 0 & human-to-human \\
\hline 3 & Phan, L. T. & 2020 & Vietnam $^{[6]}$ & 2 & 27,65 & $2(100.0)$ & 0 & 0 & 0 & human-to-human, familial cluster \\
\hline 4 & Rothe, C. & 2020 & Germany $^{[7]}$ & 1 & 33 & $1(100.0)$ & 0 & 0 & 0 & human-to-human, asymptomatic transmission \\
\hline 5 & N I R S T & 2020 & Australia $^{[5]}$ & 12 & $21-66$ & $7(58.3)$ & 0 & $1(8.3)$ & 0 & human-to-human \\
\hline 6 & Pongpirul,W.A. & 2020 & Thailand $^{[19]}$ & 1 & 51 & $1(100.0)$ & 0 & 0 & 0 & human-to-human \\
\hline 7 & Arashiro,Takeshi & 2020 & $\operatorname{Japan}^{[20]}$ & 2 & 27,35 & $1(50.0)$ & 0 & 0 & 0 & human-to-human \\
\hline 8 & Rodriguez-MoralesAJ & 2020 & Brazil $^{[9]}$ & 1 & 61 & $1(100.0)$ & 0 & 0 & 0 & human-to-human \\
\hline 9 & Shrestha R & 2020 & $\mathrm{Nepal}^{[10]}$ & 1 & 32 & 1(100.0) & 0 & 0 & 0 & human-to-human \\
\hline 10 & Silverstein WK & 2020 & Canada $^{[11]}$ & 1 & 56 & $1(100.0)$ & 0 & 0 & 0 & close contact \\
\hline
\end{tabular}




\begin{tabular}{|c|c|c|c|c|c|c|c|c|c|c|}
\hline 11 & Wang, D. & 2020 & China $^{[21]}$ & 138 & $22-92$ & $75(54.3)$ & $40(29.0)$ & $36(26.1)$ & $6(4.3)$ & human-to-human, hospital-related \\
\hline 12 & Chen, Nanshan & 2020 & China $^{[22]}$ & 99 & $21-82$ & $67(67.7)$ & 0 & $23(23.2)$ & 11(11.1) & human-to-human, close contact \\
\hline 13 & Guan, W. J. & 2020 & China $^{[23]}$ & 1099 & $47(35-58)^{*}$ & $\begin{array}{l}637 / 1096 \\
(58.12 \%)\end{array}$ & $38(3.5 \%)$ & $173(15.7)$ & $15(1.4)$ & $\begin{array}{l}\text { human-to-human, family cluster, } \\
\text { fecal-oral route? }\end{array}$ \\
\hline 14 & Huang, C. & 2020 & China $^{[24]}$ & 41 & $49(41-58)$ & $30(73.2)$ & 0 & 13(31.7) & $6(14.6)$ & human-to-human, family cluster, close contact \\
\hline 15 & Chen, Huijun & 2020 & China $^{[2]}$ & 9 & $26-40$ & 0 & 0 & 0 & 0 & close contact, familial cluster \\
\hline 16 & China $\mathrm{CDC}^{5}$ & 2020 & China $^{[25]}$ & 44672 & $30-79(86.6)^{\#}$ & 22981(51.4) & $1716(3.8)$ & $8255(18.5)$ & $1023(2.3)$ & human-to-human, close contact, familial cluster \\
\hline 17 & Shi H & 2020 & China $^{[26]}$ & 81 & $49.5 \pm 11$ & $42(51.9)$ & $15(18.5)$ & $\mathrm{NA}^{3}$ & $3(3.7)$ & human-to-human, close contact, familial cluster \\
\hline 18 & Li Q & 2020 & China $^{[27]}$ & 425 & $59(15-89)$ & $240(56.5)$ & $15(3.5)$ & NA & NA & human-to-human, close contact \\
\hline 19 & Song, F. & 2020 & China $^{[28]}$ & 51 & $16-76$ & 25(49.0) & NA & NA & NA & close contact \\
\hline 20 & Chen, L. & 2020 & China $^{[29]}$ & 29 & $56(26-79)$ & $21(72.4)$ & 0 & $14(48.3)$ & $2(6.9)$ & close contact \\
\hline 21 & Zhou, Fei & 2020 & China $^{[30]}$ & 191 & $18-87$ & $119(62.3)$ & NA & $119(62.3 \%)$ & $54(28.3)$ & human-to-human, close contact \\
\hline 22 & Xu XW & 2020 & China $^{[31]}$ & 62 & $41(32-52)$ & $35(56)$ & 0 & $1(1.6)$ & 0 & human-to-human, familial cluster \\
\hline
\end{tabular}




\begin{tabular}{|c|c|c|c|c|c|c|c|c|c|c|}
\hline 23 & Yang, W. & 2020 & China $^{[32]}$ & 149 & $45.11 \pm 13.35$ & $81(54.4)$ & 0 & 0 & 0 & human-to-human, close contact \\
\hline 24 & $\mathrm{Xu} \mathrm{YH}$ & 2020 & China $^{[33]}$ & 50 & $3-85$ & $29(58.0)$ & 0 & $13(26.0 \%)$ & NA & human-to-human, close contact \\
\hline 25 & Wang, D & 2020 & China $^{[34]}$ & 31 & $7 \mathrm{yr}$ and $1 \mathrm{mo}$ & $15(48.4)$ & 0 & 0 & 0 & close contact, familial cluster \\
\hline 26 & Liu K & 2020 & China $^{[35]}$ & 137 & $57(20-83)$ & $61(44.5)$ & 0 & NA & $16(11.7)$ & human-to-human \\
\hline 27 & Zhang JJ & 2020 & China $^{[36]}$ & 140 & $57(25-87)$ & $71(50.7)$ & $3(2.1)$ & $58(41.4)$ & NA & human-to-human, familial cluster \\
\hline 28 & Zhao W & 2020 & China $^{[37]}$ & 101 & $17-75$ & $56(55.4)$ & NA & $14(13.9)$ & NA & human-to-human, familial cluster \\
\hline 29 & Yang, Xiaobo & 2020 & China $^{[38]}$ & 52 & $59.7 \pm 13.3$ & $35(67.3)$ & NA & $52(100)$ & $32(61.5)$ & human-to-human \\
\hline 30 & Tian, Sijia & 2020 & China $^{[39]}$ & 262 & $47.5(1-94)$ & $127(48.5)$ & 0 & $46(17.6)$ & $3(1.1)$ & human-to-human, close contact, familial cluster \\
\hline 31 & $\mathrm{Xu}, \mathrm{Xi}$ & 2020 & China $^{[40]}$ & 90 & $50(18-86)$ & $39(43.3 \%)$ & NA & NA & NA & human-to-human, close contact \\
\hline 32 & Tian, S. & 2020 & China $^{[41]}$ & 2 & 73,84 & $1(50.0)$ & 0 & $1(50.0)$ & $1(50.0)$ & human-to-human \\
\hline 33 & $\mathrm{Xu}, \mathrm{Zhe}$ & 2020 & China $^{[42]}$ & 1 & 50 & $1(100.0)$ & 0 & $1(100.0)$ & $1(100.0)$ & human-to-human \\
\hline 34 & Liu qian & 2020 & China $^{[43]}$ & 1 & 85 & $1(100.0)$ & 0 & $1(100.0)$ & $1(100.0)$ & NA \\
\hline
\end{tabular}


COVID-19:2019 novel coronavirus disease; Data are median (IQR), mean (SD), n (\%), n/N (\%), rang; ${ }^{1}$ Study ID: indicate the 1 st to 34 th study; ${ }^{2}$ SS:Sample Size; ${ }^{3} \mathrm{NA}$ :not applicable; ${ }^{4} \mathrm{~N}$ I R S

$\mathrm{T}$ :National Incident Room Surveillance Team; ${ }^{5} \mathrm{CDC}$ : Centers for Disease Control and Prevention; *: indicate the the whole spectrum of age; ${ }^{\#}$ :indicate $86.6 \%$ of the patients were between the ages of 30 and 79 
medRxiv preprint doi: https://doi.org/10.1101/2020.02.20.20025601; this version posted March 19, 2020. The copyright holder for this preprint (which was not certified by peer review) is the author/funder, who has granted medRxiv a license to display the preprint in perpetuity.

All rights reserved. No reuse allowed without permission.

Table 3: The Summary of Clinical characteristics and auxiliary examination of patients infected with COVID-19

\begin{tabular}{ll} 
Variable & All Patients \\
& $(\mathrm{n}=47936)$ \\
\hline
\end{tabular}

Demographic characteristics-no./total no. (\%)

Age, range - years

Male sex

(Male:Female)

Healthcare worker the whole spectrum of age

$24805 / 47933(51.7)$

$(1.07: 1)$

$1827 / 47451(3.9)$

2430/2824 (86.0)

$1804 / 2824(63.9)$

$927 / 2675(34.7)$

$621 / 2149(28.9)$

489/2481 (19.7)

$440 / 2341(18.8)$

254/1829 (13.9)

271/2383 (11.4)

165/1390 (11.9)

$139 / 2460(5.7)$

$11 / 290(3.8)$

$136 / 2234$ (6.1)

15/403 (3.7)

21/1370 (1.5)

55/1193 (4.6)

42/475 (8.8) 


\section{Coexisting disorders-no./total no. $(\%)$}

Any

Hypertension

Diabetes

Cardiovascular disease

Cerebrovascular disease

Malignancy

Respiratory disease

Digestive disease

Kidney disease

Immunodeficiency

Laboratory findings-no./total no. (\%)

Lymphopenia $\left(10^{\wedge} 9 / \mathrm{L}\right)$

Leukopenia $\left(10^{\wedge} 9 / \mathrm{L}\right)$

Thrombocytopenia $\left(10^{\wedge} 9 / \mathrm{L}\right)$

Elevated Lactate dehydrogenase (U/L)

Elevated Aspartate aminotransferase (U/L)

Elevated Alanine aminotransferase (U/L)

\section{Radiologic findings-no./total no. (\%)}

Unilateral pneumonia

Bilateral pneumonia

Ground-glass opacity

Pulmonary consolidation or exudation

Interstitial abnormalities

Severe patients-no./total no. (\%)

Treatment-no./total no. (\%)

Respiratory support

Antiviral therapy

Antibiotic therapy
1092/1946 (56.1)

6258/23482 (26.7)

3058/23133 (13.2)

$1458 / 23482(6.2)$

997/23234 (4.3)

55/1834 (3.0)

146/23482 (0.6)

$565 / 23482(2.4)$

$91 / 2030(4.5)$

20/2072 (1.0)

4/1800 (0.2)

$1252 / 1949(64.2)$

607/2087 (29.1)

$370 / 1520(24.3)$

588/1271 (46.3)

329/1254 (26.2)

296/1285 (23.0)

167/855(19.5)

$1485 / 2158(68.8)$

1184/1943 (60.9)

257/694 (37.0)

181/1026 (17.6)

8665/47152 (18.4)

1029/2008 (51.2)

1263/2008 (62.9) 
Antifungal therapy

Use of corticosteroid

Use of immunoglobin

Mechanical Ventilation

Use of extracorporeal membrane oxygenation

Use of continuous renal-replacement therapy
$46 / 1430(3.2)$

442/2008 (22.0)

282/1683 (16.8)

210/1844 (11.4)

23/1651 (1.4)

$42 / 1651(2.5)$

Table 4 : Pulmonary pathology of SARS-CoV-2 pneumonia

\begin{tabular}{ll}
\hline Pulmonary pathology & \multicolumn{1}{c}{ SARS-CoV-2 ${ }^{[41-43]}$} \\
\hline Case number & Bilateral diffuse alveolar injury with dense fibrous mucous \\
& exudates. Significant pulmonary oedema and fibrin exudate in \\
Pathological manifestations & alveolar edema. have desquamation of pneumocytes and \\
& hyaline membrane formation. There is patchy and severe \\
& pulmonary cell proliferation and interstitial thickening with \\
inflammatory cells, multinucleated giant cells and & macrophage infiltration. These features associated with acute \\
& respiratory distress syndrome.
\end{tabular}

